Check for updates

Cite this: RSC Adv., 2017, 7, 32288

Received 25th May 2017

Accepted 19th June 2017

DOI: $10.1039 / \mathrm{c} 7 \mathrm{ra0} 860 \mathrm{~h}$

rsc.li/rsc-advances

\section{The electrochemical behavior of an aluminum alloy anode for rechargeable Al-ion batteries using an $\mathrm{AlCl}_{3}$-urea liquid electrolyte $\uparrow$}

\author{
Chen Wang, Junfeng Li, Handong Jiao, Jiguo Tu (D) and Shuqiang Jiao (D)* \\ Due to its characteristics of high capacity, low cost, being non-flammable, and involving a three-electron- \\ redox reaction, the aluminum rechargeable battery has received wide attention. Because of these \\ advantages, we focus on a low-cost aluminum alloy anode and detect the discharge/charge reaction \\ mechanism in the aluminum chloride-urea liquid electrolyte at $110-130{ }^{\circ} \mathrm{C}$. The discharge voltage of the \\ battery is about $1.9 \mathrm{~V}$ and $1.6 \mathrm{~V}$, and at the current density of $100 \mathrm{~mA} \mathrm{~g}^{-1}$ the cell can produce a specific \\ capacity of $\sim 94 \mathrm{~mA} \mathrm{~h} \mathrm{~g}^{-1}$. Compared to the pure aluminum anode, the system has a promising future \\ for high efficiency, low-cost energy storage devices.
}

\section{Introduction}

Energy is not only a foundation for the national economy and people's livelihood, but also affects the sustainable development of a country and even the whole world. The rechargeable lithium-ion battery has been subject to considerable development for nearly two decades. However, the demand for higher energy/power density and longer service life is increasing. In the large-scale application of rechargeable batteries, the shortcomings of lithium-ion batteries may ultimately reduce their price competitiveness due to lithium storage and unbalanced total lithium ion distribution. This has promoted researches on other systems which are based on sodium $(\mathrm{Na})$, magnesium $(\mathrm{Mg})$, calcium $(\mathrm{Ca})$ and aluminum $(\mathrm{Al})$ carrier ions to utilize the abundance of their electrode raw materials. ${ }^{1-13}$

Taking into account the natural rich reserves and trivalent aluminum, aluminum ion batteries have become potential options for energy storage facilities. ${ }^{14-21}$ However, due to some problems, aluminum ion batteries are still in basic research state. Such as short cycle life, cathode material excitation, and low and passivated voltage platforms. These problems are mainly due to hardly finding of suitable electrode materials and electrolyte to allow ion transfer in the reversible process. Because anions are expected to have a great effect on performance of rechargeable aluminum batteries, ${ }^{22,23}$ our group used graphite electrode materials for the new Al-ion battery, allowing the chloroaluminate anions $\left(\mathrm{AlCl}_{4}{ }^{-}\right)$to be reversibly

State Key Laboratory of Advanced Metallurgy, University of Science and Technology Beijing, Beijing, 100083, PR China. E-mail: sjiao@ustb.edu.cn

$\dagger$ Electronic supplementary information (ESI) available: Galvanostatic curves of Al alloy/PG cell in an $\mathrm{AlCl}_{3} / \mathrm{urea}=1.5$ (by mole) liquid electrolyte. The SEM and EDS images of the $\mathrm{Al}$ alloy, the cycle stability of $\mathrm{Al}$ alloy/PG and $\mathrm{Al} / \mathrm{PG}$ cell. See DOI: $10.1039 / \mathrm{c} 7 \mathrm{ra} 05860 \mathrm{~h}$ intercalated/de-intercalated. ${ }^{21}$ The battery showed excellent voltage plateau at $c a .1 .8 \mathrm{~V} v s . \mathrm{Al}^{3+} / \mathrm{Al}$, and the capacity can reach $\sim 70 \mathrm{~mA} \mathrm{~h} \mathrm{~g}^{-1}$ over 100 cycles at a current density of $100 \mathrm{~mA} \mathrm{~g}^{-1}$. At the same time, Dai's group set up a high-performance rechargeable battery. ${ }^{24}$ More recently, our group has developed a secondary aluminum battery system based on the reversible deposition/stripping of aluminum on the $\mathrm{Al}$ anode and the reversibility of the chloroaluminate anions intercalated/ de-intercalated at the graphite cathode in the non-combustible $\left(\mathrm{AlCl}_{3}\right.$-urea) liquid electrolyte. ${ }^{25}$

However, the high proportion aluminum content of aluminum anode in the $\mathrm{AlCl}_{3} /$ urea system is susceptible to be corroded, resulting in capacity decay. At the same time, according to the pure aluminum price and the uncertainty of the cathode reaction process, we select the aluminum alloy foil (thickness $0.6 \mathrm{~mm}$ ) anode, pyrolyzed graphite cathode and vacuum dried urea/ $\mathrm{AlCl}_{3}$ liquid electrolyte to reconstruct $\mathrm{Al} /$ graphite in a sealed Teflon electrolytic cell. The batteries are assembled in a Teflon cell operated at $130{ }^{\circ} \mathrm{C}$ and $120^{\circ} \mathrm{C}$. We find that the battery with the molar ratio of $\mathrm{AlCl}_{3} /$ urea to $\sim 1.4-$ 1.5 can reach $94-100 \mathrm{~mA} \mathrm{~h} \mathrm{~g}^{-1}$ (based on pyrolytic graphite mass) with a coulombic efficiency of $90-102 \%$.

\section{Experimental}

\subsection{Materials}

All materials and chemicals are commercially available and used as original. A sealed electrolytic tank was used for the Alion battery. A $15 \times 15 \mathrm{~mm}$ pyrolytic graphite carbon paper (Suzhou Dasen Electronics Material Co., Ltd., mass $10 \mathrm{mg}$ ) was fixed by using a molybdenum sheet to form the cathode. The cathode was further wrapped by a piece of glass fiber membrane (GF/A, Whatman) prior to cell assembly. An aluminum alloy foil (General Research Institute for Nonferrous Metals) $(25 \times 25$ 
$\mathrm{mm}, 0.6 \mathrm{~mm}$ thickness) was used as the anode. Fig. S3† shows the SEM and EDS images of aluminum alloy before testing and after 80 cycles. Before testing, both graphite and aluminum alloy were put into the beaker and washed them with deionized water in the ultrasonic cleaner. Then aluminum alloy was dried in the vacuum oven; meanwhile, pyrolytic graphite was put into the centrifuge, and also dried in the vacuum oven after repeated centrifugal treatment.

\subsection{Electrochemical measurements}

The battery was packaged in a glove box using PG ( 10 mg) cathode and Al alloy foil anode. Urea is firstly added to the beaker and then aluminum chloride is added. After dissolution, the formed solution was transferred into a Teflon electrolytic tank and sealed by PTFE lid electrode.

The charge/discharge of the cell was performed using a Neware BTS-53 tester. On the basis of the mass of the pyrolytic graphitic paper, we calculated the specific capacity and current density. Cyclic voltammetry (CV) measurements were performed at a scan rate of $0.5 \mathrm{mV} \mathrm{s}^{-1}$ using a two-electrode configuration with $\mathrm{CHI}$ electrochemical analyser (CHI 660E).

\subsection{Characterization}

Using X-ray diffractometer (XRD, Rigaku, D/max-RB), Raman spectroscopy (Horiba-labram HR evolution) and X-ray photoelectron spectroscopy (XPS, Kratos AXIS Ultra DLD) to detect the crystal structure of the samples. The morphology was characterized by field emission scanning electron microscopy (FESEM, JEOL, JSM-6701F).

\section{Results and discussion}

Fig. 1a and b represent the charge and discharge curves at 110$130{ }^{\circ} \mathrm{C}$. The cut-off voltage is set in the range of $0.4 \mathrm{~V}$ to $2.18 \mathrm{~V} v$. $\mathrm{Al}^{3+} / \mathrm{Al}$. The charge and discharge behaviors are obvious, with the average discharge voltage platform of $1.9 \mathrm{~V}$ and $1.6 \mathrm{~V}$ ( $v s$. $\mathrm{Al}^{3+} / \mathrm{Al}$ ), respectively. We can see from Fig. $1 \mathrm{a}$ and $\mathrm{b}$, the specific capacity in the $\mathrm{AlCl}_{3}$ /urea (by mole) = 1.5 electrolyte is higher than the $\mathrm{AlCl}_{3}$ /urea (by mole) $=1.4$ electrolyte when temperature is the same. As the temperature is elevated, the specific capacity is also increased.

Fig. 1c suggests the cyclic voltammetry $(\mathrm{CV})$ of the aluminum alloy anode and the pyrolytic graphite cathode in the $\mathrm{AlCl}_{3}$ /urea (by mole) $=1.5$ electrolyte, which yields the battery with the highest specific capacity with good electrochemical performance. Two obvious oxidation peaks in the 1.6-1.9 V range, while another well-defined peak appeared at $\sim 2.05 \mathrm{~V}$ (Fig. 1c and d). It can be inferred that the process of this battery is different from the lithium-ion battery, which may occur a number of reactions. Because aluminum ion is a multivalent ion, it can form a variety of ions with the electrolyte, which is necessary to explore the role of the electrolyte in the cell system. These processes, as well as the corresponding reduction events on the negative sweep, were easily correlated with the galvanostatic charge-discharge curve (Fig. 1a and $\mathrm{b}$ ) for a battery with $\sim 4.45 \mathrm{mg} \mathrm{cm}^{-2}$ loading of active pyrolytic graphitic material. There are two reasons why the existence of the polarization voltage: (1) Al ions and coordination ions are too large to limit the diffusion of these ions in the electrolyte and the embedding and de-embedding in the pyrolytic graphite layer. (2) Al alloy passivation films can also inhibit the deposition and dissolution of $\mathrm{Al}$. Most importantly, $\mathrm{AlCl}_{3} /$ urea $=1.5$ at $130{ }^{\circ} \mathrm{C}$ is the best condition for generating the battery (Fig. S2 $\dagger$ ).

In order to keep Coulomb efficiency $>90 \%$, the cut-off voltage of the aluminum alloy/PG battery was set at $2.18 \mathrm{~V}$, and the highest efficiency was observed (Fig. 2a). The low efficiency is probably due to generate side reactions (particularly above $2.18 \mathrm{~V}$ ) in the electrolyte.

Current density reflects the rate of an electrochemical reaction, when the current is small, the use of active material is more fully; when the current is larger, the electrode polarization is relatively large, hence the use of the active material may not be sufficient. Taking into account the different current density (100, 150, $200 \mathrm{~mA} \mathrm{~g}^{-1}$ ), aluminum alloy/PG battery in 30 cycles almost maintain its specific capacity of $90 \pm 5 \%$ coulombic efficiency (Fig. 2b). The initial coulombic efficiency is more than $100 \%$, mainly because the PG cathode is not fully soaked by electrolyte in the first cycles, causing the battery not fully charged. We can see that the specific capacity can reach $105 \mathrm{~mA} \mathrm{~h} \mathrm{~g}^{-1}$ at the beginning with the current density of $100 \mathrm{~mA} \mathrm{~g}^{-1}$ (Fig. S2 $\dagger$ ). Subsequently, the specific capacity gradually decreased, and tends to stabilize at $\sim 94 \mathrm{~mA} \mathrm{~h} \mathrm{~g}^{-1}$, showing a large capacity performance. Even at $150 \mathrm{~mA} \mathrm{~g}^{-1}$ and $200 \mathrm{~mA} \mathrm{~g}^{-1}$, the discharge capacity is maintained at $92.48 \mathrm{~mA} \mathrm{~h} \mathrm{~g}^{-1}$ and $87.72 \mathrm{~mA} \mathrm{~h} \mathrm{~g}^{-1}$. The attenuation of the capacitance may be caused by the evaporation of the electrolyte and the instability of the pyrolytic graphite. Moreover, it can be seen that the aluminum alloy before the reaction is very flat, and the aluminum alloy electrode after 80 cycles is partially corrosion. However, the electrode is still smooth, and do not appear dendritic aluminum. According to previous research, the aluminum alloy is cheaper and better corrosion resistance than pure aluminum foil. Further on, SEM and EDS images of the $\mathrm{Al}$ alloy before cycling and after 80 cycles indicate the surface of the alloy composition has not changed basically (Fig. S3†). It is well known that the $\mathrm{Mg}$ containing compound in alloy has a more negative electrode potential than that of the aluminum matrix, which is firstly dissolved in the electrochemical reaction as anode. Low content of $\mathrm{Mg}$ can reduce intergranular corrosion, the hydrogen evolution and corrosion rate, and hence improve the electrochemical performance of aluminum anode. Therefore, it can be speculated that the aluminum alloy can be used directly as the negative electrode in the $\mathrm{Al}$ ion battery (Fig. 2c and $\mathrm{d}$ ).

XRD measurements of pyrolytic graphite paper (Fig. 3a) show that intercalation/de-intercalation of chloroaluminate anions during charge and discharge. The sharp peak of the charged graphite changed from $26.54^{\circ}$ to $27.22^{\circ}$ and the new peak appeared at $22.82^{\circ}$. The bimodal XRD peak represents a graphene laminate that forms a high strain on the anion intercalation. ${ }^{24}$ When fully charged, the graphite peak shifts to $27.22^{\circ}$ and the wide shoulder may be due to the irreversible change in the accumulation of graphene layers or a small amount of trapping material. The Raman spectra of the original PG and the 80th cycle of charged and discharged pyrolytic graphite (PG) 

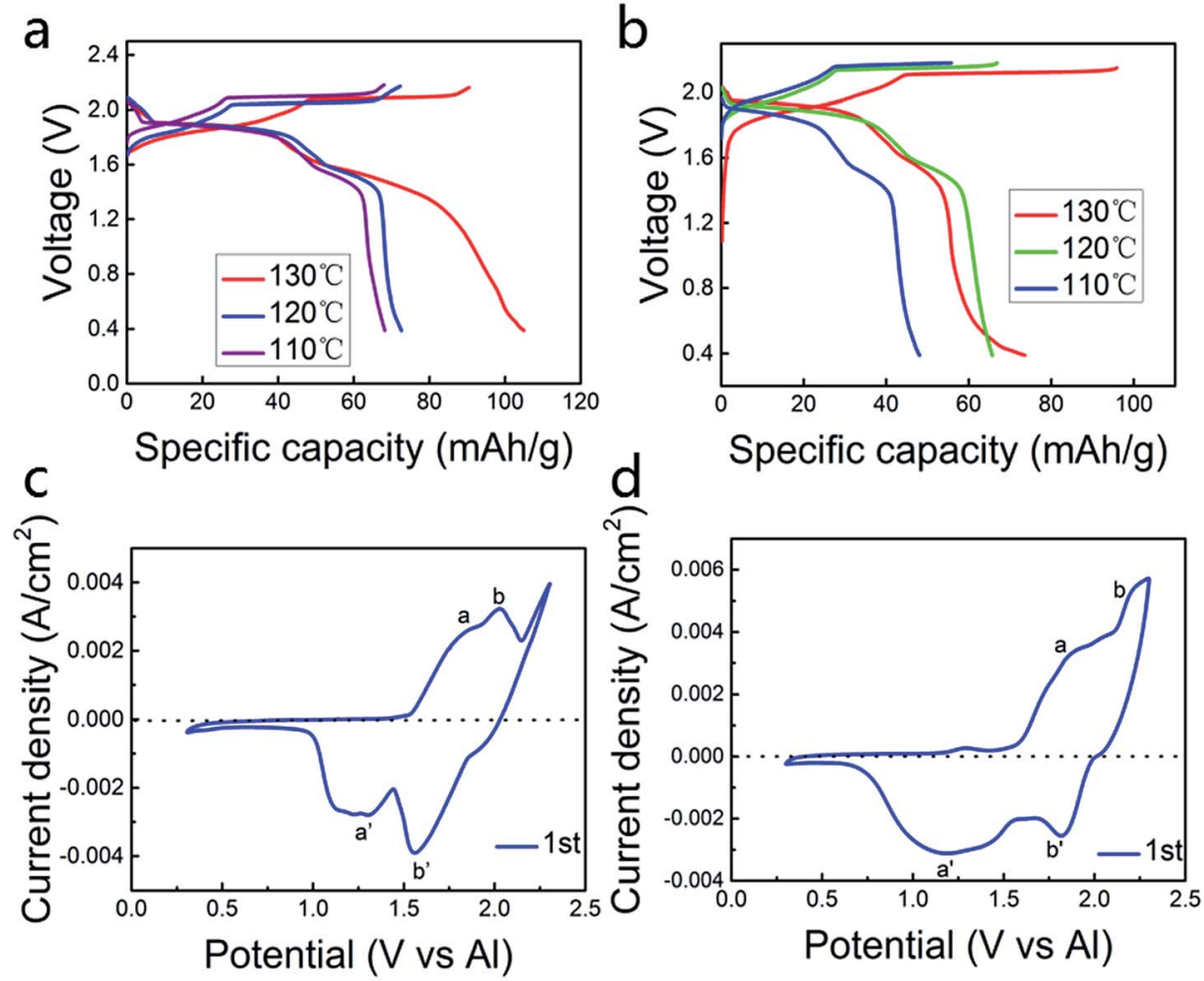

Fig. 1 (a) A current curve of an aluminum alloy/PG battery at $100 \mathrm{~mA} \mathrm{~g}^{-1}$ with different temperature in $\mathrm{AlCl}_{3} / \mathrm{urea}=1.5$ (by mole) liquid electrolyte, and (b) a current curve in $\mathrm{AlCl}_{3} /$ urea $=1.4$ liquid electrolyte. Cyclic voltammetry curve of an aluminum alloy/PG at $0.5 \mathrm{mV} \mathrm{s}^{-1}$ (c) in an $\mathrm{AlCl}_{3} /$ urea $=1.5$ liquid electrolyte and (d) in an $\mathrm{AlCl}_{3} / \mathrm{urea}=1.4$ liquid electrolyte.
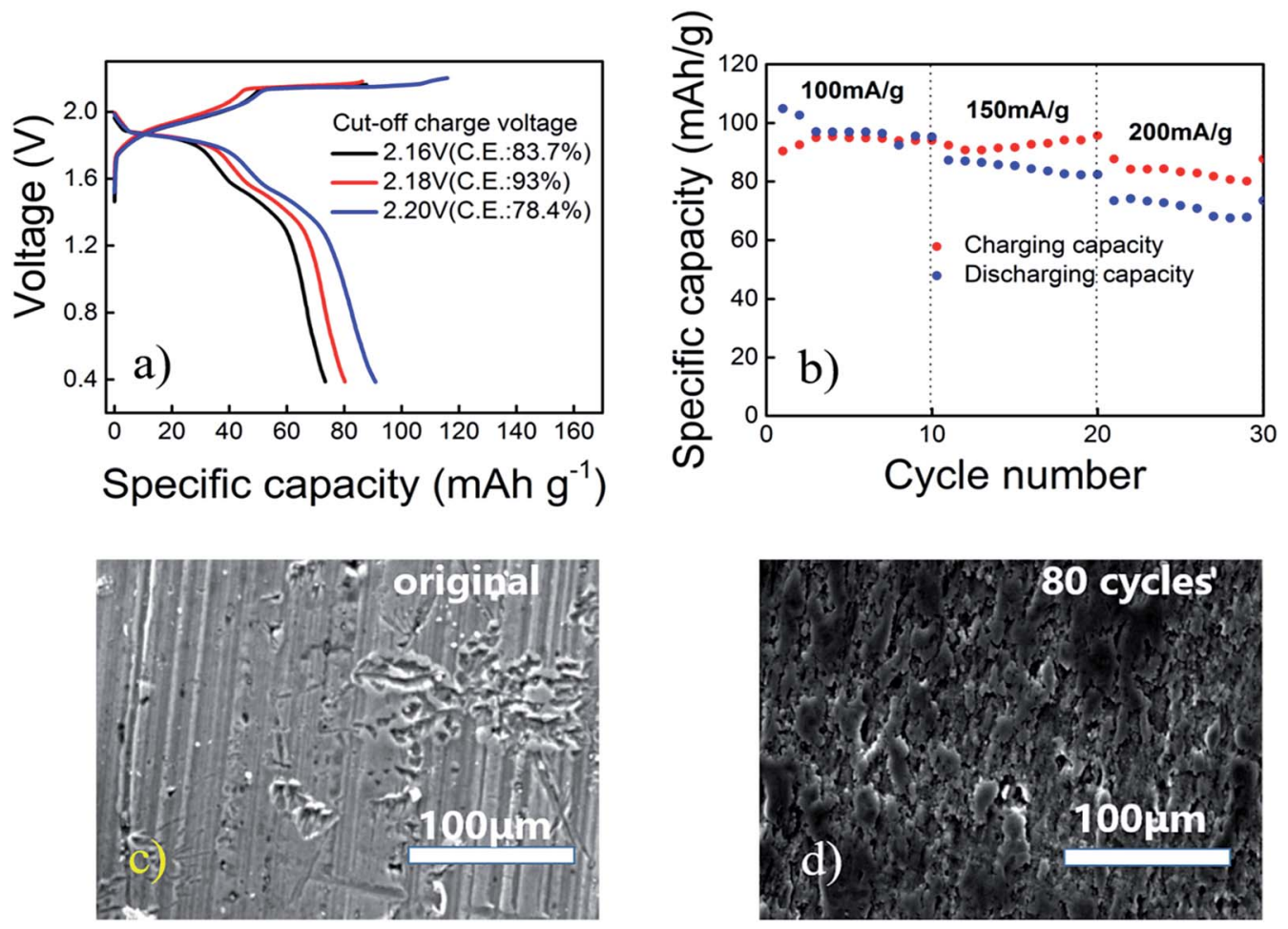

Fig. 2 (a) Galvanostatic curves of aluminum alloy/PG cells with different cut-off charge voltages obtained at $100 \mathrm{~mA} \mathrm{~g}{ }^{-1}$ in a Teflon electrolytic tank. (b) An aluminum alloy/PG cell charging and discharging at current densities ranging from 100 to $200 \mathrm{~mA} \mathrm{~g}^{-1}$. SEM images of the original $\mathrm{Al}$ alloy (c) and anode obtained from aluminum alloy/PG cells after 80 (d) cycles, respectively, and indicate no dendrite formation over these cycles. 
a)

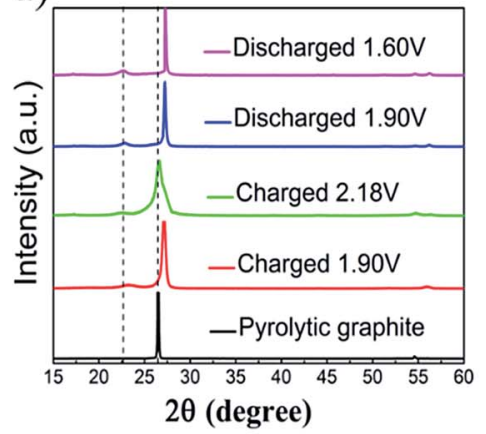

c)

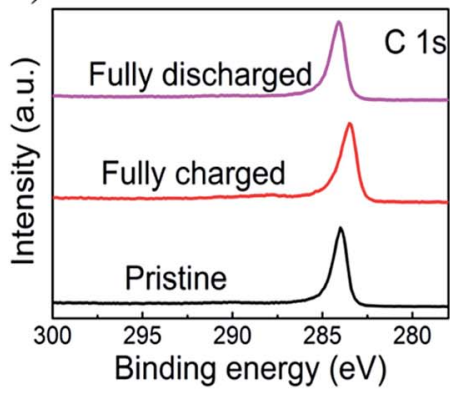

d)

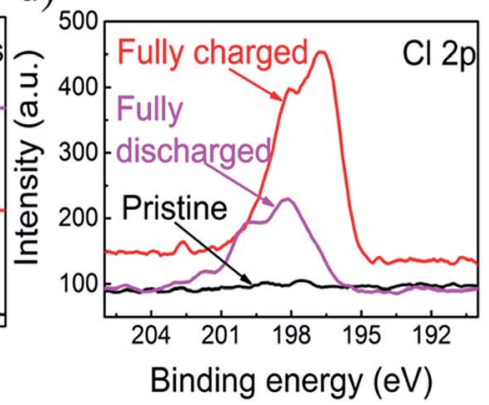

b)

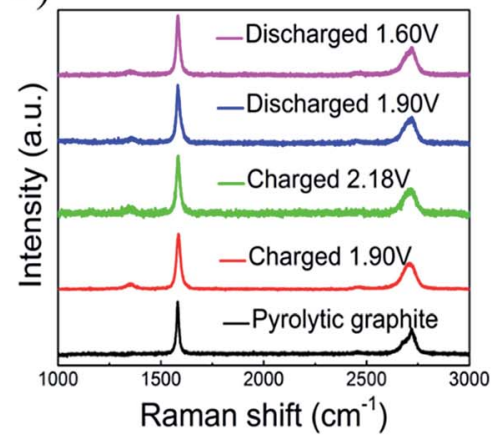

e)

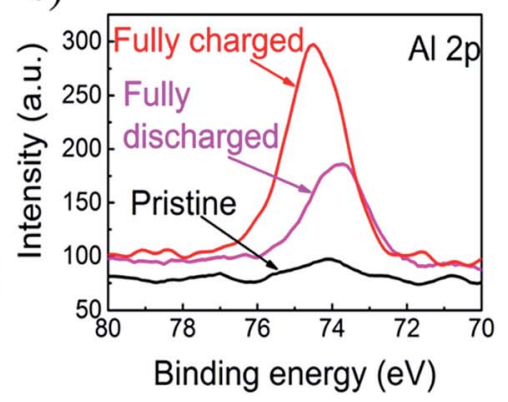

Fig. 3 (a) X-ray diffraction patterns of PG in different charging and discharging states. (b) Raman spectra recorded for the PG cathode through a charge-discharge cycle, showing chloroaluminate anion intercalation/de-intercalation into pyrolytic graphite. (c) XPS data of the C 1s peak of a graphitic-foam electrode: pristine, fully charged and fully discharged. XPS data of Al $2 p$ (d) and Cl $2 p$ peaks (e) observed with a PG paper electrode: pristine, fully charged and fully discharged.

were showed in the Fig. 3 . There are two peaks, in which the first one is at $1352 \mathrm{~cm}^{-1}$ (D band), and the second one is at 1580 $\mathrm{cm}^{-1}$ (G band). D-band refers to the presence of structural disorders and defects in the carbon material. It can be found that the D-band was strengthened through the charging process, suggesting that the intercalation of chloroaluminate ions increases the structural defects and disorders on both edges of graphite. The G-band corresponds to the crystallinity of the graphite, ${ }^{26,27}$ mainly because of the vibrations of $\mathrm{sp}^{2}$ bonded carbon atoms in a two-dimensional hexagonal lattice..$^{27-29}$ During the process from charging to discharging, the D peak is gradually reduced and the degree of graphitization is increasing. Almost no significant difference shows that PG structure is basically unchanged after the charge and discharge.

The X-ray photoelectron spectrometer (XPS) spectra of the primitive, charged and discharged pyrolytic graphite (PG) paper were showed in Fig. 3c-e. The X-ray photoelectron spectrometer is applied to detect the chemical properties of intercalated substances in PG cathodes. So as to reduce the amount of the captured electrolyte, the cathode was sufficiently washed with deionized water and absolute ethanol. There are no differences between the original and cycled pyrolytic graphite in the C 1 s XPS peaks graphic, ${ }^{30}$ and also no essential information regarding the intercalation/deintercalation can be observed (Fig. 3c). For the fully charged state, the intercalation of the chloroaluminate ion is demonstrated by the increase in the $\mathrm{Al} 2 \mathrm{p}$ and $\mathrm{Cl} 2 \mathrm{p}$ peaks relative to discharge state (Fig. $3 \mathrm{~d}$ and e).
When the cut-off voltage of the aluminum alloy/pyrolytic graphite (PG) battery was set to $2.18 \mathrm{~V}$, the aluminum alloy/PG cell shows an apparent discharge voltage platform in the range of 1.9-1.8 $\mathrm{V}$ and $1.7-1.5 \mathrm{~V}$ (Fig. 4). A fairly high discharge voltage platform is excellent in a number of previous Al-ion storage systems. The charge-discharge cycle shows an excellent

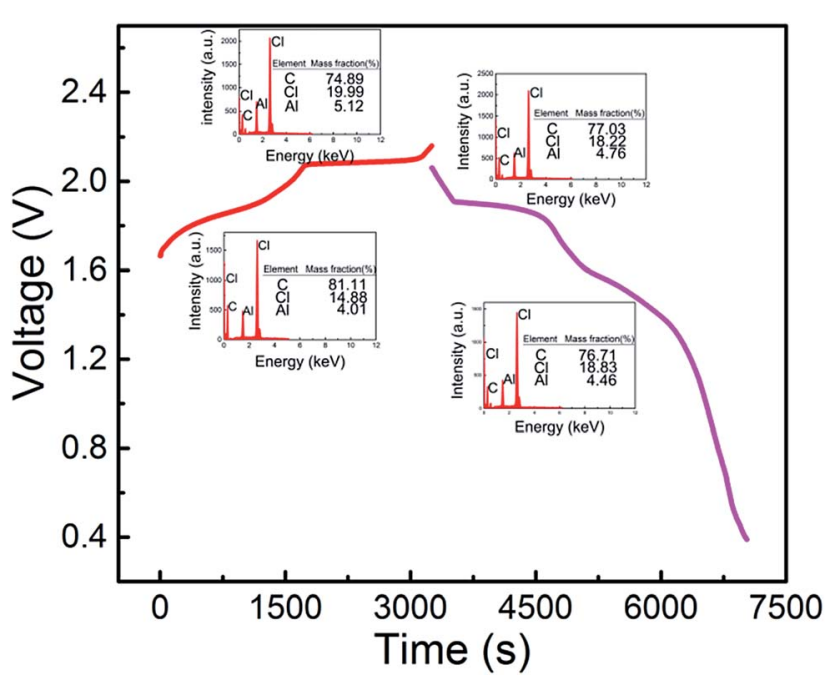

Fig. 4 Galvanostatic charge and discharge curves of an aluminum alloy/pyrolytic graphite (PG) cell at a current density of $100 \mathrm{~mA} \mathrm{~g}^{-1}$. Inset, energy dispersive spectrometer (EDS) at different plateaus. 
electrochemical characteristic of the battery even at $100 \mathrm{~mA} \mathrm{~g}^{-1}$. The EDS mapping is showed in Fig. 4. For the fully charged state, the intercalation of chloroaluminate ions was evidenced by the increased of $\mathrm{Al}$ and $\mathrm{Cl}$ elements relative to the discharged state. Furthermore, the mass fraction ratio of $\mathrm{Al} / \mathrm{Cl}$ approximate $4: 1$, which strongly confirmed that chloraluminate ions were inserted/removed into the graphitic carbon.

And then, we investigated the speciation in several $\mathrm{AlCl}_{3} /$ urea electrolytes. Raman spectroscopy has previously been used to reveal the existence of chloroaluminate anions in the electrolytes (Fig. 5). We observed the characteristic Raman shifts of $\mathrm{AlCl}_{4}{ }^{-}\left(311 \mathrm{~cm}^{-1}\right)$ and $\mathrm{Al}_{2} \mathrm{Cl}_{7}^{-}\left(349 \mathrm{~cm}^{-1}\right)$ for $\mathrm{AlCl}_{3} /$ urea $=1.5$. Since $\mathrm{Al}_{2} \mathrm{Cl}_{7}{ }^{-}$exists in our $\mathrm{AlCl}_{3} /$ urea $=1.5$ electrolyte used for the $\mathrm{Al}$ battery. The possible reactions (eqn (1)-(3)) in the $\mathrm{AlCl}_{3}$ / urea system are proposed as follows: $:^{25,31,32}$

$$
\begin{gathered}
n(\text { Urea })+\mathrm{AlCl}_{3} \rightarrow\left[\mathrm{AlCl}_{2} \cdot n(\text { urea })\right]^{+}+\mathrm{AlCl}_{4}^{-} \\
\mathrm{AlCl}_{4}^{-}+\mathrm{AlCl}_{3} \rightarrow \mathrm{Al}_{2} \mathrm{Cl}_{7}^{-} \\
\mathrm{Al}_{2} \mathrm{Cl}_{7}^{-}+\mathrm{AlCl}_{3} \rightarrow \mathrm{Al}_{3} \mathrm{Cl}_{10}^{-}
\end{gathered}
$$

where $n$ is the coordination number of urea and controlled by the mole ratio of $\mathrm{AlCl}_{3}$ to urea, $\left[\mathrm{AlCl}_{2} \cdot n \text { (urea) }\right]^{+}$is the cationic species in the mixture. With the increase in molar ratio, there are more $\mathrm{AlCl}_{3}$ in the system, resulting in the generation of $\mathrm{Al}_{2} \mathrm{Cl}_{7}{ }^{-}$. Therefore, when the mole ratio of $\mathrm{AlCl}_{3}$ to urea is 1.5, both $\mathrm{AlCl}_{4}{ }^{-}$and $\mathrm{Al}_{2} \mathrm{Cl}_{7}{ }^{-}$anions are present in the electrolyte.

Schematic drawing of the cell using an $\mathrm{AlCl}_{3} /$ urea liquid electrolyte are suggested and illustrated in Fig. 6. During charging process, $\left[\mathrm{AlCl}_{2} \cdot n \text { (urea) }\right]^{+}$cations were transformed into metallic $\mathrm{Al}$ and $\mathrm{AlCl}_{4}{ }^{-}$anions at the anode, meanwhile predominantly $\mathrm{AlCl}_{4}{ }^{-}$anions were intercalation between graphite layers at the cathode. And the reverse reaction occurs during discharging process. The reaction of the electrode is suggested as follows:

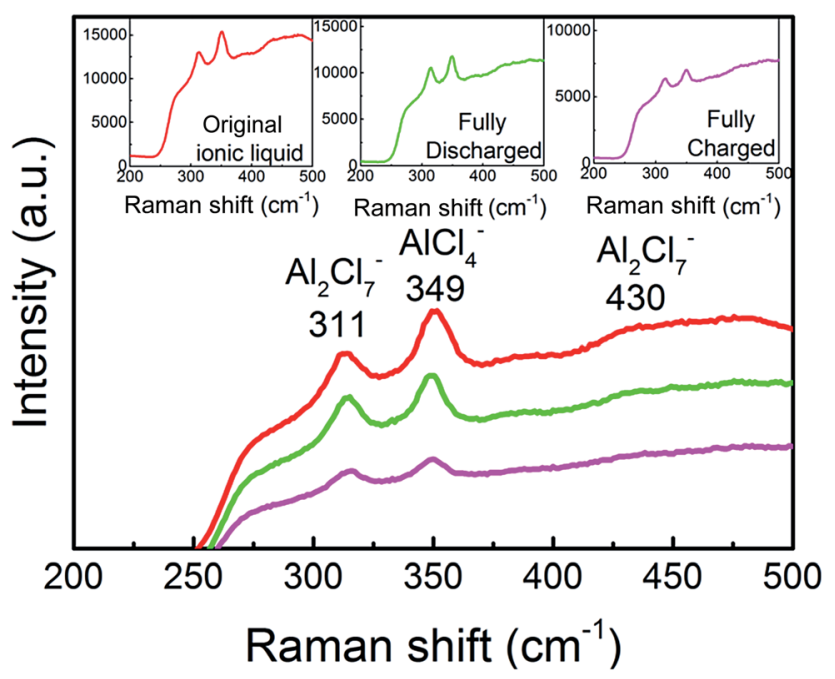

Fig. 5 Raman spectra of the ionic liquid electrolyte with a mole ratio of $\mathrm{AlCl}_{3} /$ urea $=1.5$. Inset, Raman spectra of original, fully charged and fully discharged liquid electrolyte.

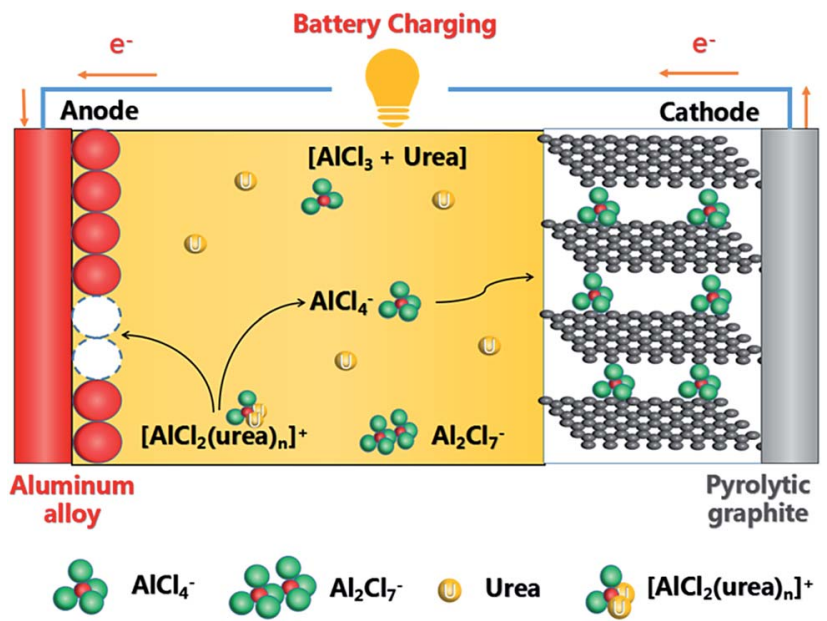

Fig. 6 Schematic drawing of the cell during charging using an $\mathrm{AlCl}_{3} /$ urea liquid electrolyte.

Anode:

$$
\begin{gathered}
2\left[\mathrm{AlCl}_{2} \cdot n(\text { urea })\right]^{+}-3 \mathrm{e}^{-} \rightleftharpoons \mathrm{Al}+\mathrm{AlCl}_{4}^{-}+2 \text { nurea } \\
4 \mathrm{Al}_{2} \mathrm{Cl}_{7}^{-}+3 \mathrm{e}^{-} \rightleftharpoons \mathrm{Al}+7 \mathrm{AlCl}_{4}^{-}
\end{gathered}
$$

Cathode:

$$
\begin{gathered}
\mathrm{C}_{n}+\mathrm{AlCl}_{4}^{-} \rightleftharpoons \mathrm{C}_{n}\left[\mathrm{AlCl}_{4}\right]+\mathrm{e}^{-} \\
\mathrm{C}_{n}+\mathrm{Al}_{2} \mathrm{Cl}_{7}^{-} \rightleftharpoons \mathrm{C}_{n}\left[\mathrm{Al}_{2} \mathrm{Cl}_{7}\right]+\mathrm{e}^{-}
\end{gathered}
$$

\section{Conclusion}

In this work, with a high and obvious voltage plateau, a novel Alion battery based on an $\mathrm{Al}$ alloy anode, pyrolytic graphite paper cathode, and low-priced $\mathrm{AlCl}_{3}$-urea liquid analogue electrolyte were successfully established. Intercalation/de-intercalation of chloroaluminate anions during charging/discharging was confirmed by Raman experiments. The present $\mathrm{Al}$ alloy/PG battery can afford almost $105 \mathrm{~mA} \mathrm{~h} \mathrm{~g}^{-1}$. The battery is costcompetitive in commercial and deserved further investigation. While this work represents an exciting step forward, exploration of numerous combinations of electrolytes and electrode materials remains wide open for further development of $\mathrm{Al}$ batteries to achieve ultra-high energy density/cost ratios.

\section{Acknowledgements}

This work was supported by the Fundamental Research Funds for the Central Universities (FRF-TP-15-002C1).

\section{References}

1 W. Wang, B. Jiang, W. Xiong, H. Sun, Z. Lin, L. W. Hu, J. Tu, J. Hou, H. Zhu and S. Jiao, Sci. Rep., 2013, 3, 3383. 
2 A. Ponrouch, C. Frontera, F. Bardé and M. R. Palacín, Nat. Mater., 2016, 15, 169-172.

3 D. Larcher and J. M. Tarascon, Nat. Chem., 2015, 7, 19-29.

4 Z. Yang, J. Zhang, M. C. Kintner-Meyer, X. Lu, D. Choi, J. P. Lemmon and J. Liu, Chem. Rev., 2011, 111, 3577-3613.

5 N. Yabuuchi, K. Kubota, M. Dahbi and S. Komaba, Chem. Rev., 2014, 114, 11636-11682.

6 H. D. Yoo, I. Shterenberg, Y. Gofer, G. Gershinsky, N. Pour and D. Aurbach, Energy Environ. Sci., 2013, 6, 2265-2279.

7 S. Y. Hong, Y. Kim, Y. Park, A. Choi, N. S. Choi and K. T. Lee, Energy Environ. Sci., 2013, 6, 2067-2081.

8 S. Y. Lim, H. Kim, J. Chung, J. H. Lee, B. G. Kim, J. J. Choi, K. Y. Chung, W. Cho, S. J. Kim, W. A. Goddard III, Y. Jung and Y. Jung, Proc. Natl. Acad. Sci. U. S. A., 2014, 111, 599-604.

9 K. W. Nam, S. Kim, E. Yang, Y. Jung, E. Levi, D. Aurbach and J. W. Choi, Chem. Mater., 2015, 27, 3721-3725.

10 Z. Chen, Y. Ren, A. N. Jansen, C. K. Lin, W. Weng and K. Amine, Nat. Commun., 2013, 4, 1513.

11 S. Tepavcevic, H. Xiong, V. R. Stamenkovic, X. Zuo, M. Balasubramanian, V. B. Prakapenka, C. S. Johnson and T. Rajh, ACS Nano, 2011, 6, 530-538.

12 Y. Zhu, Y. Wen, X. Fan, T. Gao, F. Han, C. Luo, S. C. Liou and C. Wang, ACS Nano, 2015, 9, 3254-3264.

13 J. Sun, H. W. Lee, M. Pasta, H. Yuan, G. Zheng, Y. Sun, Y. Li and Y. Cui, Nat. Nanotechnol., 2015, 10, 980-985.

14 W. Lv, Z. Li, Y. Deng, Q. Yang and F. Kang, Energy Storage Materials, 2016, 2, 107-138.

15 N. Jayaprakash, S. K. Das and L. A. Archer, Chem. Commun., 2011, 47, 12610-12612.

16 S. Liu, J. Hu, N. Yan, G. Pan, G. Li and X. Gao, Energy Environ. Sci., 2012, 5, 9743-9746.
17 J. V. Rani, V. Kanakaiah, T. Dadmal, M. S. Rao and S. Bhavanarushi, J. Electrochem. Soc., 2013, 160, A1781A1784.

18 N. S. Hudak, J. Phys. Chem. C, 2014, 118, 5203-5215.

19 S. Liu, G. Pan, G. Li and X. Gao, J. Mater. Chem. A, 2015, 3, 959-962.

20 Z. Li, K. Xiang, W. T. Xing, W. C. Carter and Y. M. Chiang, Adv. Energy Mater., 2015, 5, 1401410.

21 H. Sun, W. Wang, Z. Yu, Y. Yuan, S. Wang and S. Jiao, Chem. Commun., 2015, 51, 11892-11895.

22 H. Wang, S. Gu, Y. Bai, S. Chen, N. Zhu, C. Wu and F. Wu, J. Mater. Chem. A, 2015, 3, 22677-22686.

23 H. Wang, S. Gu, Y. Bai, S. S. Chen, F. Wu and C. Wu, ACS Appl. Mater. Interfaces, 2016, 8, 27444-27448.

24 M. Lin, M. Gong, B. Lu, Y. Wu, D. Wang, M. Guan, M. Angell, C. Chen, J. Yang, J. Y. Hwang and H. Dai, Nature, 2015, 520, 324-328.

25 H. Jiao, C. Wang, J. Tu, D. Tian and S. Jiao, Chem. Commun., 2017, 53, 2331-2334.

26 G. S. Zakharova, C. Jahne, A. Popa, C. Täschner, T. Gemming, A. Leonhardt, B. Büchner and R. Klingeler, J. Phys. Chem. C, 2012, 116, 8714-8720.

27 P. L. S. G. Poizot, S. Laruelle, S. Grugeon, L. Dupont and J. M. Tarascon, Nature, 2000, 407, 496-499.

28 Y. Wang, F. Su, C. D. Wood, J. Y. Lee and X. S. Zhao, Ind. Eng. Chem. Res., 2008, 47, 2294-2300.

29 Y. Song, S. Jiao, J. Tu, J. Wang, Y. Liu, H. Jiao, X. Mao, Z. Guo and D. J. Fray, J. Mater. Chem. A, 2017, 5, 1282-1291.

30 P. S. Bagus, E. S. Ilton and C. J. Nelin, Surf. Sci. Rep., 2013, 68, 273-304.

31 P. Wasserscheid and W. Keim, Angew. Chem., Int. Ed., 2000, 39, 3772-3789.

32 A. C. Ferrari, Solid State Commun., 2007, 143, 47-57. 